\title{
Characterization of the rat basilar artery in vitro
}

\author{
R.J. Winquist ${ }^{1}$ and D.F. Bohr \\ Department of Physiology, University of Michigan Medical School, Ann Arbor (Michigan 48109, USA), I0 March 1982
}

Summary. Segments of the rat basilar artery were examined in vitro for their mechanical responsiveness to a variety of vasoactive substances. Serotonin was the most potent agonist while norepinephrine elicited a dose-dependent relaxation. The findings lend support to the concept that there exists a marked heterogeneity amongst species in cerebrovascular responsiveness.

Much of our knowledge on blood vessel abnormalities in the pathogenesis of cardiovascular disease comes from studies on vascular reactivity in the various disease models produced in the laboratory rat ${ }^{2-4}$. However, surprisingly little is known about cerebral vessel responsiveness in this animal even though a genetic model of stroke has been developed $^{5}$. Studies on isolated cerebral arteries have been confined to specimens from large laboratory animals ${ }^{6-9}$ due to the constraints of in vitro methodologies.

The advent of small artery instrumentation ${ }^{10}$ now makes it possible to examine individual pial vessels under conditions where factors difficult to regulate in situ can be precisely controlled. Our reasons in deciding to characterize the rat basilar artery were 2 -fold: 1 . large vessels at the base of the brain are believed to be important regulators of cerebral blood flow ${ }^{11,12}$ and 2 . our results would allow a species comparison since the basilar artery is often utilized when studying responsiveness of isolated cerebral arteries.

Methods and materials. Adult male Sprague-Dawley rats (250-300 g) were anesthetized with ether and exsanguinated. The brain was quickly removed from the skull and placed in cold physiological salt solution (PSS) ${ }^{9}$. The basilar artery was dissected free and mounted on fine tungsten filament wires $(32 \mu \mathrm{m})$ in a $20-\mathrm{cm}^{3}$ horizontal chamber for recording isometric tension as described previously ${ }^{10} .1 \mathrm{~mm}$ segments of the basilar artery just distal to the confluence of the vertebral arteries were examined. The dual chamber apparatus contained oxygenated $\operatorname{PSS}\left(95 \% \mathrm{O}_{2} / 5 \% \mathrm{CO}_{2}\right)$ at $37^{\circ} \mathrm{C}$ which was replaced every $20 \mathrm{~min}$ while tissues were equilibrated for $1 \mathrm{~h}$ without any resting force. After the equilibration period, tissue segments were subjected to a resting force of $250 \mathrm{mg}$ which allowed for maximal active force generated to depolarizing solution $\left(130 \mathrm{mM} \mathrm{K} \mathrm{K}^{+}\right)$. Contractile responses to agonists were expressed as a percentage of the maximal response to depolarizing solution. The concentration of spasmogen that produced a response equal to $50 \%$ of the maximal contraction to

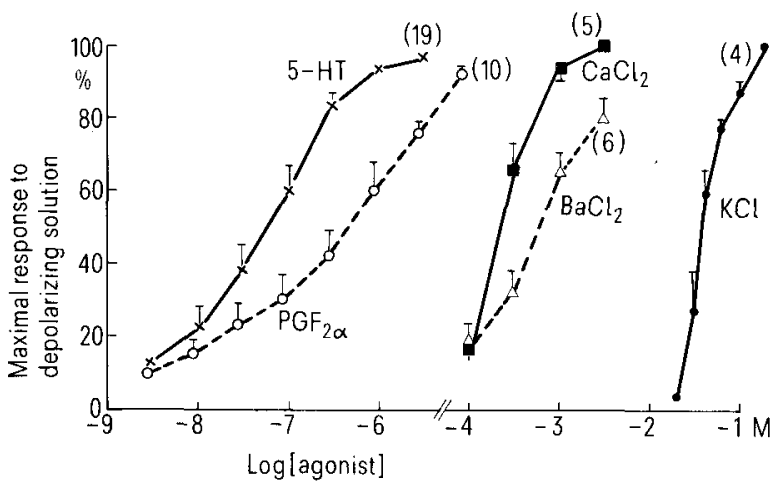

Figure 1. Contractile dose-response curves to serotonin $(5-\mathrm{Ht}, \mathrm{X})$, prostaglandin $\mathrm{F}_{2 a}\left(\mathrm{PGF}_{2 a}, \mathrm{O}\right) \mathrm{CaCl}_{2}$ (readdition of $\mathrm{CaCl}_{2}$ in depolarized preparations, $\mathbf{D}), \mathrm{BaCl}_{2}(\triangle)$ and $\mathrm{KCl}(\boldsymbol{O})$ in isolated rat basilar artery rings. All responses are expressed as a percentage of the maximal response to depolarizing solution $\left(130 \mathrm{mM} \mathrm{K}^{+}\right)$. The number of experiments for each agonist is shown in parentheses. Values are means $\pm S E M$. depolarizing solution $\left(\mathrm{EC}_{50}\right)$ was calculated by transforming the drug concentrations to log values and performing a linear regression analysis using the method of least squares. A similar methodology was utilized to calculate the concentration of norepinephrine or isoproterenol which caused a $50 \%$ relaxation $\left(\mathrm{IC}_{50}\right)$ of the contraction to exogenously added $\mathrm{PGF}_{2 a}\left(3 \times 10^{-6} \mathrm{M}\right)$ or serotonin $\left(3 \times 10^{-7} \mathrm{M}\right)$.

Drugs used were: norepinephrine bitartrate (Breon Laboratories, Inc.); serotonin, prostaglandin $\mathrm{F}_{2 a}$ (Sigma Chemical Co.) and isoproterenol hydrochloride (Elkins-Sinn Co.). Results and discussion. Isolated segments of the rat basilar artery contracted to a variety of spasmogens (fig. 1). The most potent agonist tested was serotonin $(5-\mathrm{HT})$ which also elicited a near-maximal contraction in these tissues. 5-HT has been reported as one of the most potent vasoconstrictors on basilar and other cerebral arteries from human ${ }^{13}$ $\operatorname{dog}^{13,14}$ and cat ${ }^{15}$. The table lists the maximal force and $\mathrm{EC}_{50}$ values for the contractile agents.

An unexpected finding was the lack of response to exogenously added norepinephrine (NE). However, both NE and isoproterenol (ISO) dose-dependently relaxed basilar artery segments which were previously contracted with prosta-

The maximum force generated and $\mathrm{EC}_{50}$ for various spasmogens on the rat basilar artery

\begin{tabular}{|c|c|c|c|}
\hline Spasmogen (n) & $\begin{array}{l}\text { Maximum } \\
\text { force }^{l}(\mathrm{mg})\end{array}$ & $\begin{array}{l}\mathrm{EC}_{50} \\
\text { (moles/l) }\end{array}$ & $\begin{array}{l}\text { Relative activity } \\
\text { to serotonin } \\
\mathrm{EC}_{50} \text { serotonin } \\
\mathrm{EC}_{50} \text { spasmogen }\end{array}$ \\
\hline Serotonin (19) & $839 \pm 33$ & $3.5 \times 10^{-8}$ & 1.0 \\
\hline $\mathrm{PGF}_{2 a}$ & $832 \pm 49$ & $2.4 \times 10^{-7}$ & 0.2 \\
\hline $\mathrm{CaCl}_{2}$ & $861 \pm 66$ & $2.3 \times 10^{-4}$ & $1.5 \times 10^{-4}$ \\
\hline $\mathrm{BaCl}_{2}$ & $757 \pm 84$ & $3.6 \times 10^{-4}$ & $9.7 \times 10^{-5}$ \\
\hline $\mathrm{KCL}^{2}$ & $888 \pm 71$ & $3.4 \times 10^{-2}$ & $1.0 \times 10^{-6}$ \\
\hline
\end{tabular}

${ }^{1}$ Values are means \pm SEM

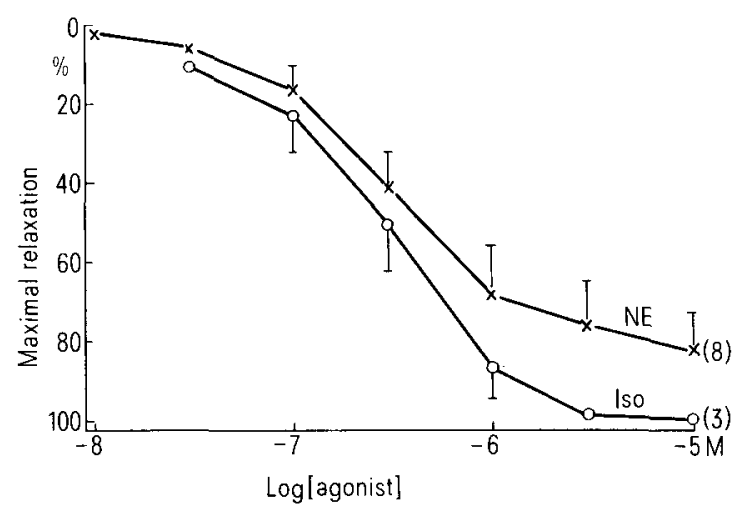

Figure 2. Relaxant dose-response curves to exogenously added norepinephrine (NE, X) and isoproterenol (Iso, O) in isolated rat basilar artery rings previously contracted by either serotonin $\left(3 \times 10^{-7} \mathrm{M}\right)$ or $\mathrm{PGF}_{2 a}\left(3 \times 10^{-6} \mathrm{M}\right)$. All responses are expressed as a percent decrease of the spasmogen contraction. The number of experiments is shown in parenthesis. Values are means \pm SEM. 
glandin $\mathrm{F}_{2 a}$ or 5-HT (fig. 2). The $\mathrm{IC}_{50}$ 's for NE and ISO were $4.4 \times 10^{-7} \mathrm{M}$ and $2.7 \times 10^{-7} \mathrm{M}$, respectively. Cerebral vessels from most species except the pig ${ }^{9,16}$ constrict in response to NE; $\beta$-adrenoceptor-mediated relaxation is observed only after prior pharmacological blockade of $a$-adrenoceptors ${ }^{8}$. The similar potency of NE and ISO in relaxing the rat basilar artery imply the presence of $\beta_{1}$ subclass of adrenoceptors. This is consistent with that reported previously for cerebral vessels ${ }^{8,9}$.

1 Present address: Merck Institute for Therapeutic Research, West Point, (Pennsylvania 19486, USA). This work was supported by grants from the National Institutes of Health (NIHLBI-06080, 18575)

2 Jones, A., and Hart, R., Circulation Res. 37(1975) 333.

3 Folkow, B., Clin. Sci. molec. Med. 55 (1978) 3s

4 Winquist, R., Webb, R., and Bohr, D., Fedn Proc., 41 (1982) 2387.

5 Okamoto, K., Yamori, Y., and Nagaoka, A., Circulation Res. 34 and 35 suppl. 1 (1974) 143.

6 Duckles, S., Lee, T., and Bevan, J., in: Neurogenic control of the brain circulation, p. 133. Eds. C. Owman and L. Edvinsson. Pergamon Press, Oxford 1977.

7 Toda, N., in: Neurogenic control of the brain circulation, p.207. Eds. C. Owman and L. Edvinsson. Pergamon Press, Oxford 1977
The findings on the rat basilar artery support the contention of 5-HT being the most potent cerebrovascular constrictor. However, the predominant $\beta$-adrenoceptormediated relaxation further demonstrates the marked heterogeneity in the responsiveness of isolated cerebral arteries amongst species. Direct $\beta$-adrenergic relaxation may be responsible for the increased cerebrovascular flow in rats following i.v. infusion of NE after osmotic opening of the blood brain barrier ${ }^{17}$

8 Edvinsson, L., Acta physiol. scand. suppl. 427, (1976) 1.

9 Winquist, R., and Bohr, D., Circulation Res., submitted.

10 Mulvany, M., and Halpern, W., Circulation Res. 41 (1977) 19.

11 Kontos, H., Wei, E., Navari, R., Levasseur, J., Rosenblum, W, and Patterson, J Am. J Physiol. 234 (1978) H371.

12 Mchedlishvili, G., Stroke 11 (1980) 240.

13 Toda, N., and Fujita, Y., Circulation Res. 33 (1973) 98.

14 Allen, G., Henderson, L., Chou, S., and French, L., J. Neurosurg. 40 (1974) 433

15 Nielsen, K., and Owman, C., Brain Res. 27 (1971) 33.

16 Winquist, R., and Bohr, D., Physiologist 23 (1980) 60.

17 Edvinsson, L., Lacombe, P., Owman, C., Reynier-Rebuffel, A. and Seylaz, J., Acta physiol. scand. 107 (1979) 289.

\section{Cyclic AMP concentration in the rat's preoptic region ${ }^{1}$}

\section{G. Zamboni, E. Perez and P. L. Parmeggiani ${ }^{2}$}

Istituto di Fisiologia umana, Università di Bologna, Piazza di Porta San Donato 2, I-40127 Bologna (Italy), 3 December 1981

Summary. In rats adapted to a 12:12 h light-dark (LD) schedule, cyclic AMP concentration in the preoptic region showed a $\mathrm{L}$ minimum and D maximum. No significant fluctuations were observed in the parietal cortex.

Daily fluctuations in cyclic AMP concentration have been observed in the cerebrospinal fluid of rhesus monkeys $s^{3,4}$ and in several structures of rat encephalon, including the hypothalamus ${ }^{5}$ and the pineal gland ${ }^{6}$.

This study was performed to clarify whether daily fluctuations of cyclic AMP concentration occur in the preoptic region of the rat. It is well known that preoptic-hypothalamic mechanisms underlie the control of daily rhythms of several functional systems ${ }^{7-10}$. As a control, cyclic AMP concentration was concomitantly determined in the parietal cortex.
188 male Sprague-Dawley rats (160-180 g), housed in individual cages (Ta $22 \pm 0.5^{\circ} \mathrm{C}$; food and water ad libitum) and adapted for a week to a $12: 12 \mathrm{~h}$ light-dark (LD) schedule (07.00-19.00 h L), were used. Cyclic AMP concentration in the preoptic region and parietal cortex was studied in animals killed at fixed intervals by immersion in liquid nitrogen. The removal of samples of the preoptic region ${ }^{11}$ and the parietal cortex (in the same frontal plane of the preoptic region and close to the interhemispheric fissure) from brain slices previously stored at $-80^{\circ} \mathrm{C}$, was performed by means of $0.8 \mathrm{~mm}$ i.d. needles in a dry-ice

Hourly and half-day (Lc, Dc) cyclic AMP concentrations (pmoles/mg protein, mean \pm SEM) during light and dark periods in the preoptic region and the parietal cortex, and cosine function $\left(\mathrm{Y}=\mathrm{C}_{0}+\mathrm{C} \cos (\omega \mathrm{t}-\varnothing)^{\circ}\right)$ fitting the data. Between brackets is the number of observations; $\mathrm{H}_{0}$, null hypothesis; $\mathrm{C}$, cosine function amplitude; $\mathrm{F}$, Fisher's $\mathrm{F}$; df, degrees of freedom; NS, not significant

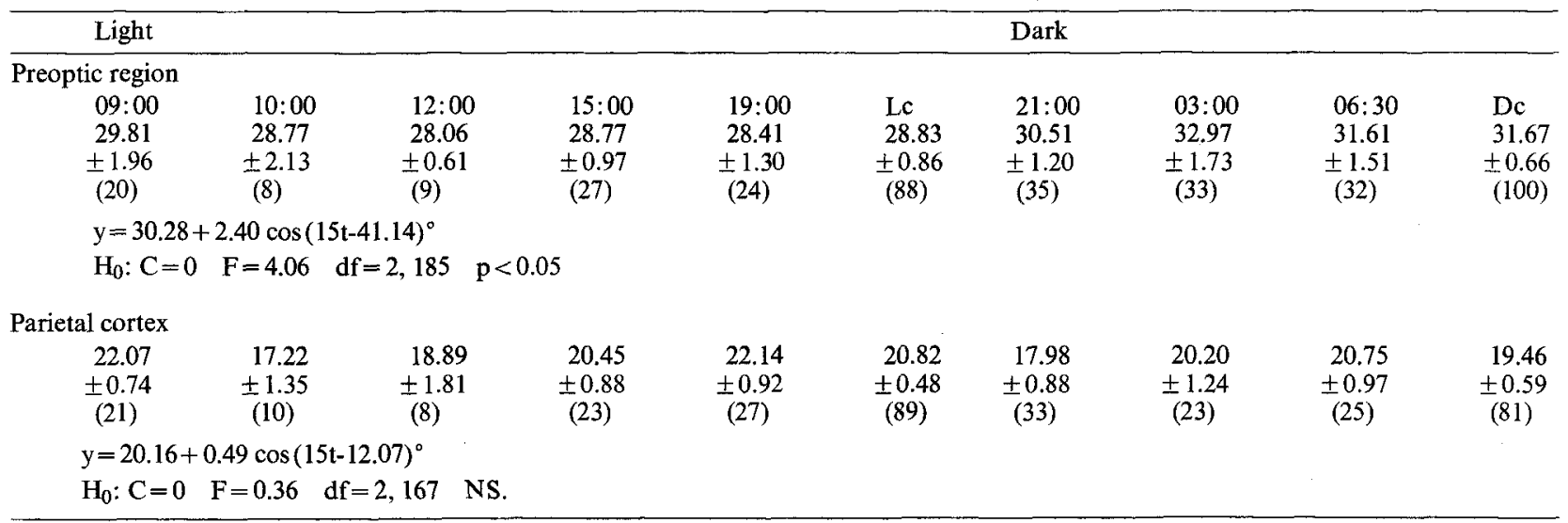

